\title{
Large complex ovarian cyst managed by laparoscopy
}

\section{Dipak J. Limbachiya, Ankit Chaudhari, Grishma P. Agrawal*}

Department of Obstetrics and Gynaecology, EVA Endoscopy Training Institute, Ahmadabad, Gujarat, India

Received: 08 December 2016

Accepted: 31 December 2016

\section{*Correspondence:}

Dr. Grishma P. Agrawal,

E-mail: grishma.agrawal29@gmail.com

Copyright: () the author(s), publisher and licensee Medip Academy. This is an open-access article distributed under the terms of the Creative Commons Attribution Non-Commercial License, which permits unrestricted non-commercial use, distribution, and reproduction in any medium, provided the original work is properly cited.

\begin{abstract}
Complex ovarian cyst with secondary infection is a rare disease that hardly responds to the usual antibiotic treatment. Most of the times, it hampers day to day activities of women. It is commonly known to cause pain and fever. To our surprise, in our case the cyst was large enough to compress the ureter and it was adherent to the surrounding structures. Laparoscopic removal of the cyst was done and specimen was sent for histopathological examination.
\end{abstract}

Keywords: Infertility, Laparoscopy, Ovarian cyst

\section{INTRODUCTION}

Large ovarian cyst and accumulation of pus inside, is an uncommon condition but its prompt diagnosis and management is vital. It can be a functional cyst like follicular cyst, corpus luteum cyst, theca lutein cyst, chocolate cyst or it can be a neoplastic one. ${ }^{1}$

Symptomatic patients commonly present with abdominal pain, although most of the patients are asymptomatic and the cysts were found accidently by bimanual examination or ultrasound. Pain can present as dull ache or pain in the lower back or abdomen. ${ }^{2}$ Sometimes patients present with prolonged infertility and a huge ovarian cyst is an accidental finding. Acute severe pain can occur in complicated ovarian cysts, torsion, infarction, or hemorrhage. ${ }^{2}$ Torsion of cyst, infection and adhesion formation are rare presentations but have increased morbidity.

Any evaluation of a patient with an ovarian cyst should include a thorough medical history and a complete physical examination in the search of warning signs of malignancy. The medical history should focus of risk factors and red flags for malignancy. It is also important to search for symptoms suggesting endometriosis, especially in this cohort of patients reproductive-age women with infertility. ${ }^{3}$ The physical examination should include an abdominal and pelvic examination including a bimanual pelvic examination. Treatment depends on combination of clinical, bio chemical markers like CA125 as well as sonography findings. If cyst seems to be infected then FNAC and culture sensitivity are also useful. $^{4}$

\section{CASE REPORT}

A 27 years old patient, nulligravida presented with complaint of dull pain in lower abdomen with moderate intensity, relieved intermittently by taking analgesics along with low grade fever on and off since six months. She also complained of continuous episodes of vomiting since two days bilious in nature but small in amount. Her menstrual cycle was normal. She had primary infertility of ten years. She had no significant past history.

Her ultrasonography suggested $12 * 10 * 6 \mathrm{~cm}$ sized cystic lesion with low level internal echoes with septa in Pouch of Douglas. Left ovary was not visualised separately. Another $7 * 6 * 5 \mathrm{~cm}$ sized haemorrhagic cyst was seen adjacent to it. Uterus and right ovary were normal. Her CA-125 was 13.73. Blood reports showed thrombocytosis. Rest other investigations were normal. Patient was taken for laparoscopy. Intra operatively, there was a large left ovarian cyst adherent to the rectum and omentum, Due to pressure effect, there was left hydro 
ureter. Right ovary and uterus were normal. Left oophorectomy was done and the cyst was sent for frozen section.

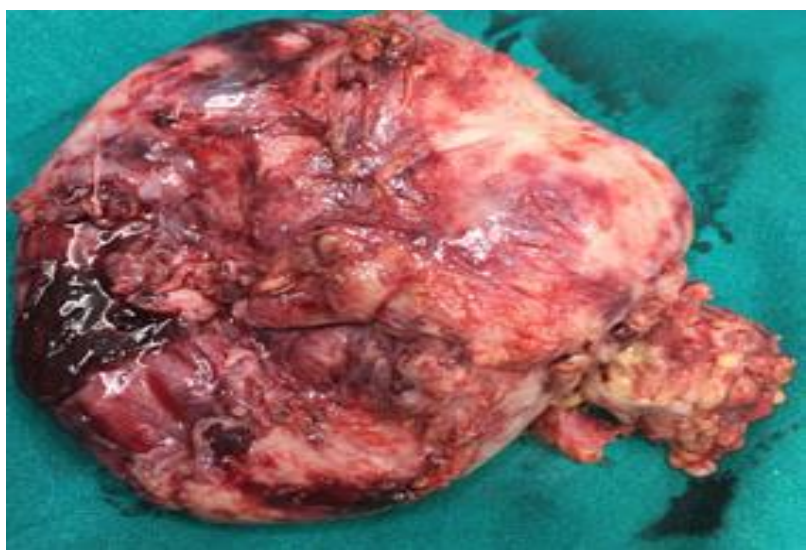

Figure 1: Specimen of removed ovarian cyst.

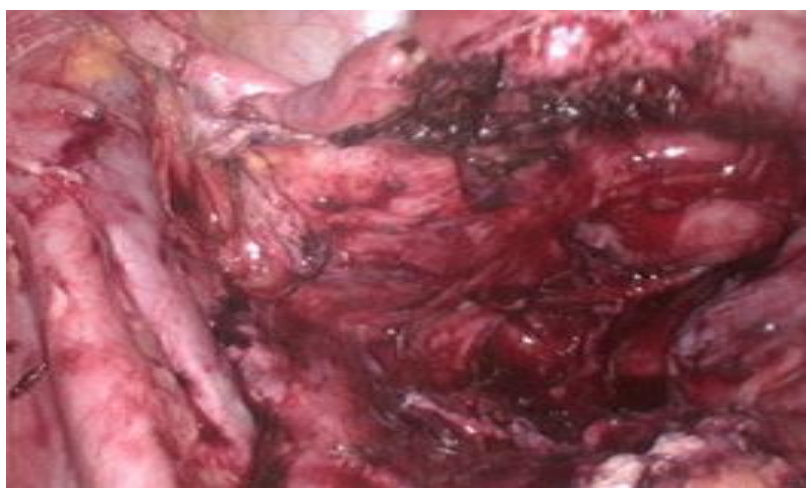

Figure 2: Final endo view of pelvis after removal of cyst.

Report of frozen section showed inflammatory mass consistent with nonspecific abscess, left tubo-ovarian mass. Postoperative antibiotics were given according to the culture and sensitivity report. Patient was discharged on day 3.

\section{DISCUSSION}

Ovarian cyst can affect any female, from premenarche to postmenopause, regardless of race or ethnicity or fertility. The percentage of women affected is between $11 \%$ to $72 \%$. It is more common in women with endometriosis, pelvic inflammatory disease and multiple ovulation induction.

Symptoms of ovarian cyst are variable. Not all patients develop abdominal pain but it is the most common presentation. Patients may present with an abdominal lump or infertility but many patients conceive and are diagnosed in the antenatal period. ${ }^{5}$ In our case presentation was fever due to infection of the cyst. Formation of hydronephrosis in our case was only due to pressure effect of the cyst which was completely relieved after removal of the cyst. Patient needed antibiotics according to the sensitivity of organism cultured from pus. Ovarian mass $>6 \mathrm{~cm}$ in diameter needs visualization with laparoscopy or exploratory laparotomy. In a systematic review, that included six randomized controlled trials comparing the laparoscopic approach to laparotomy for ovarian cysts has shown reduced febrile morbidity, less postoperative pain, lower rates of postoperative complications, earlier discharge from hospital and lower overall cost. ${ }^{6}$ Some surgeons limited laparoscopic surgery to ovarian cyst of size less than 10 $\mathrm{cm} \cdot{ }^{7-10}$ For apparently benign, extremely large ovarian cysts, only few surgeons advocate laparoscopic management. ${ }^{11-14}$ Salem reported 15 cases of large benign ovarian cysts reaching above the level of the umbilicus, which were managed laparoscopically. ${ }^{15}$ Intra operative frozen biopsy helps to complete extensive surgery in a single sitting if any malignant potential of the cyst is found. Patient can resume her normal lifestyle earlier as compared to open surgery.

\section{CONCLUSION}

Large ovarian cyst can be removed by different ways according to the factors like expertise of surgeon, fertility of patient, pre-operative reports and availability of instruments. But the best way is to remove it by minimal invasive techniques and intra operative frozen biopsy. It prevents unnecessary repeat surgery and helps in radical cure if required in a single sitting.

Funding: No funding sources Conflict of interest: None declared Ethical approval: Not required

\section{REFERENCES}

1. Rock JA, Jones HW. Te Linde's Operative Gynecology 10th ed; 2010:632-635.

2. Goh W, Bohrer J, Zalud I. Management of the adnexal mass in pregnancy. Curr Opin Obstet Gynecol. 2014;26:49-53.

3. Ballard KD. Can symptomatology help in the diagnosis of endometriosis? Findings from a national case-control study Part 1. International Journal of Obstetrics and Gynaecology. 2008;115:1382-91.

4. Rock JA, Jones HW. Te Linde's Operative Gynecology 10th ed.; 2010:632-635.

5. Padubidri VG, Daftary SN. Shaw's Textbook of Gynecology 16th edition. 2015:448.

6. Medeiros LR. Laparoscopy versus laparotomy for benign ovarian tumor: A systematic review and meta-analysis. International Journal of Gynecological Cancer. 2008;18:387-99.

7. Mais V, Ajossa S, Piras B, Marongiu D, Guerriero S, Melis GB. Treatment of nonendometriotic benign adnexal cysts: A randomized comparison of laparoscopy and laparotomy. Obstet Gynecol. 1995;86:770-4. 
8. Pittaway DE, Takacs P, Bauguess P. Laparoscopic adnexectomy: A comparison with laparotomy. Am J Obstet Gynecol. 1994;171:385-91.

9. Nezhat F, Nezhat C, Welander CE, Benigno B. Four ovarian cancers diagnosed during laparoscopic management of 1011 women with adnexal masses. Am J Obstet Gynecol. 1992;167:790-6.

10. Lin P, Falcone T, Tulandi T. Excision of ovarian dermoid cyst by laparoscopy and by laparotomy. Am J Obstet Gynecol. 1995;173:769-71.

11. Nezhat F, Nezhat C, Welander CE, Benigno B. Four ovarian cancers diagnosed during laparoscopic management of 1011 women with adnexal masses. Am J Obstet Gynecol. 1992;167:790-6.

12. Lin $\mathrm{P}$, Falcone T, Tulandi T. Excision of ovarian dermoid cyst by laparoscopy and by laparotomy. Am J Obstet Gynecol. 1995;173:769-71.
13. Howard FM. Surgical management of benign cystic teratoma: Laparoscopic vs laparotomy. J Reprod Med. 1995;40:495-9.

14. Amos NN, Brodbent JA, Hill NC, Magos AL. Laparoscopic "oophorectomy-in-a-bag" for removal of ovarian tumors of uncertain origin. Gynecol Endoscop.

15. Salem HA. Laparoscopic excision of large ovarian cysts. J Obstet Gynaecol Res. 2002;28:290-4.

Cite this article as: Limbachiya DJ, Chaudhari A, Agrawal GP. Large complex ovarian cyst managed by laparoscopy. Int J Reprod Contracept Obstet Gynecol 2017;6:769-71. 